\title{
Penilaian Perumahan Berdasarkan Kriteria Rumah Sehat Menggunakan Metode Fuzzy Multicriteria Decision Making
}

\author{
Muhammad Hadi Saputra ${ }^{1}$, Azrai Sirait ${ }^{2}$ \\ ${ }^{1}$ Universitas Adiwangsa Jambi \\ Jambi, Indonesia \\ ${ }^{2}$ Program Studi Teknik Informatika, Fakultas Teknik Universitas Asahan \\ Kisaran, Indonesia \\ 1hadihirataegmail.com, 2azraijhonegmail.com
}

\begin{abstract}
Abstrak - Rumah yang sehat sangat penting bagi kehidupan manusia. Keuntungannya dapat menghindarkan dari berbagai penyakit berbasis lingkungan seperti penyakit ISPA yang banyak diderita oleh balita, tubercolusis, diare dan menghindarkan dari penyakit yang dibawa oleh vektor seperti demam berdarah, malaria, PES dan Filariasis. Selain terhindar dari berbagai penyakit rumah yang sehat dapat mempengaruhi perilaku sehat pada manusia yang berpengaruh terhadap kualitas sumber daya manusia. Maka dari itu perlu diadakannya penilaian secara berkala untuk menilai perumahan berdasarkan kriteria rumah sehat agar semua keinginan yang diharapkan dapat tercapai dengan baik. Penggunaan metode pada kasus perumahan ini yaitu Fuzzy Multi Criteria Decision Making (FMCDM) yang mana metode ini akan memberikan suatu keputusan untuk permasalahan yang dihadapi. Metode ini membantu melakukan pengambilan keputusan pada keadaan yang banyak terdapat alternatif kriteria..
\end{abstract}

Keywords - Sistem Pendukung Keputusan, Fuzzy Multi Criteria Decision Making,Rumah Sehat

\section{PENDAHULUAN}

\section{A. Latar Belakang}

Sistem informasi berbasis komputer dapat digunakan dalam memecahkan masalah berupa pengambilan keputusan yang sering disebut dengan sistem pendukung keputusan (Decision Support System) yang dapat membantu setiap orang dalam menentukan pilihan akan suatu permasalahan yang dihadapi (Antoni Aruan,2014). Salah satu metode yang sering dipakai dalam system pendukung keputusan (Decision Support System) yaitu Fuzzy Multi Criteria Decision Making. Multicriteria Decision Making Methods (MCDM) adalah sebuah metode yang mengacu pada proses screening, prioritizing,ranking, atau memilih set alternatif (dalam hal ini dapat berupa "candidate" atau "action") dengan kriteria yang bersifat independent, incommensurate atau conflicting (Rika Rosnelly dan Retantyo Wardoyo, 2011)

Fuzzy Multi Criteria Decision Making pada saat ini sudah banyak dipergunakan dalam melakukan pengambilan suatu keputusan, salah satu contohnya Anjali, et al (2009), menyatakan pengukuran kesuksesan pada suatu manajemen, Rika dan Retantyo (2011), menjelaskan Sistem Pendukung Keputusan menggunakan Fuzzy Multi Criteria Decision Making untuk pendiagnosaan penyakit tropis.

Cang et al (2009) menyatakan penggunaan metode Fuzzy Multi Criteria Decision Making dalam pendekatan kemungkinan kesuksesan dalam sebuah manajemen. Jurgita et al (2015) menyatakan penggunaan metode Fuzzy Multi Criteria Decision Making pada bidang teknik sipil Hidgeet (2015) menjelaskan penggunaan metode Fuzzy Multi Criteria Decision Making dalam pemilihan suatu peralatan, Kahraman et al (2014) juga menyatakan penggunaan Fuzzy multi Criteria Decision Making sebagai literatur pustaka.
Menurut UU RI No. 4 Tahun 1992, rumah adalah struktur fisik terdiri dari ruangan, halaman dan area yang dipakai sebagai tempat tinggal dan sarana pembinaan keluarga. Komisi WHO (World Health Organization) Mengenai Kesehatan dan Lingkungan Tahun 2001 mengatakan bahwa rumah adalah struktur fisik atau bangunan untuk tempat berlindung, dimana lingkungan berguna untuk kesehatan jasmani dan rohani serta keadaan sosialnya baik untuk kesehatan keluarga dan individu.

Sandang, pangan termasuk didalamnya papan (rumah) merupakan kebutuhan primer seorang manusia. Perumahan merupakan kebutuhan dasar manusia dan juga merupakan faktor yang berpengaruh pada kesehatan masyarakat. Perumahan yang layak untuk tempat tinggal harus memunuhi syarat kesehatan sehingga penghuninya tetap sehat. Perumahan yang sehat tidak lepas dari ketersediaan prasarana dan sarana yang terkait, seperti penyediaan air bersih, sanitasi pembuangan sampah, transportasi, dan tersedianya pelayanan social (Tri Afriliyanti dan Sri Winiarti,2013).

Untuk mengetahui persantase jumlah perumahan berdasarkan kriteria rumah sehat dilakukan survei yang biasanya diselenggarakan oleh sanitarian puskesmas atau petugas kesehatan lingkungan kabupaten/kota dibawah pengawasan Dinas Kesehatan kabupaten. Pengambilan sample dalam melakukan pengumpulan data membutuhkan waktu yang lama karena surveyor melakukan survei dalam jumlah yang banyak.

Penilaian perumahan berdasarkan kriteria rumah sehat seharusnya menggunakan sistem perhitungan yang sesuai pedoman dari Departemen Kesehatan, namun selama ini penilaian rumah sehat yang dilakukan oleh petugas sanitarian puskesmas hanya berdasarkan PHBS (Perilaku Hidup Bersih dan Sehat). Aspek penilaian berdasarkan Departemen Kesehatan terdiri dari 3 kategori utama yaitu kategori komponen 
rumah, sarana sanitasi dan perilaku penghuni dengan beberapa kriteria.

Dari uraian di atas, penulis mengangkat judul peneltian " Perancangan Sistem Pendukung Keputusan Penilaian Perumahan berdasarkan Kriteria Rumah Sehat Menggunakan Metode Fuzzy Multi Criteria Decision Making (Studi Kasus DiKomplek Perumahan Perumahan Desa Kasang Pudak) ".

\section{B. Metode Penelitian}

Untuk memberikan panduan dalam penyusunan penelitian ini maka perlu adanya susunan kerangka kerja yang jelas tahapan-tahapannya. Seperti yang terlihat pada gambar berikut.

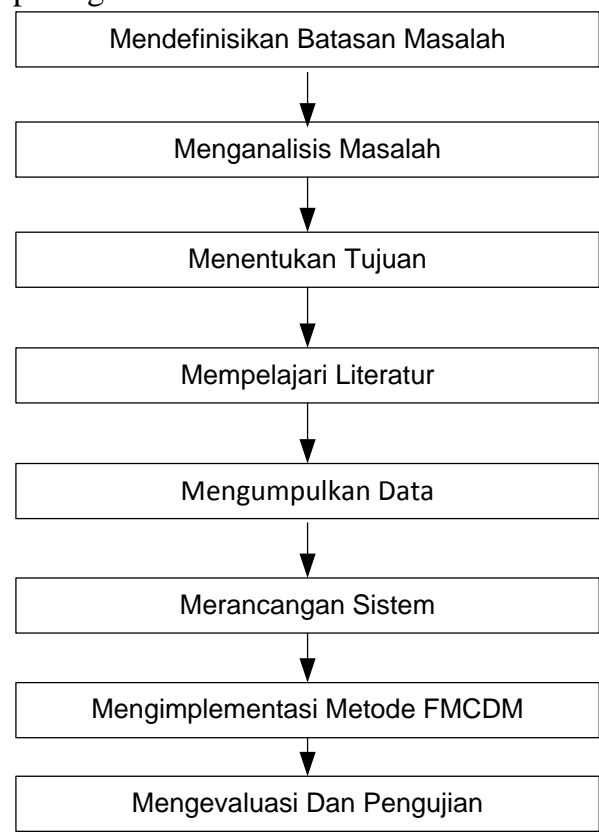

Gambar 1 Kerangka Kerja Penelitian

\section{HASIL DAN PEMBAHASAN}

\section{A. Analisis Masalah}

Penilaian rumah sehat seharusnya menggunakan sistem perhitungan yang sesuai pedoman dari Departemen Kesehatan, Aspek penilaian berdasarkan Departemen Kesehatan terdiri dari 3 kategori utama yaitu kategori komponen rumah, sarana sanitasi dan perilaku penghuni dengan beberapa kriteria dan manfaat dari adanya sistem ini terhindar dari berbagai penyakit rumah yang sehat dapat mempengaruhi perilaku sehat pada manusia yang berpengaruh terhadap kualitas sumber daya manusia.

\section{B. Analisis Konsep Fuzzy Multi Criteria Decision Making}

Penggunaan metode Fuzzy Multi Criteria Decision Making (FMCDM) merupakan suatu metode yang bisa membantu dalam melakukan pengambilan keputusan terhadap beberapa alternative keputusan yang akan diambil dengan beberapa kriteria dan derajat kecocokan pada setiap alternatif yang ada. Alternatif - alternatif dalam penilaian perumahan berdasar kriteria rumah sehat diambil dari data rumah-rumah yang ada di setiap perumahan rakyat yang ada di desa Kasang Pudak Kecamatan Kumpe Ulu Kabupaten Muaro Jambi. Untuk pengambilan data penulis menilai 5 rumah warga di setiap perumahan di Desa Kasang Pudak sebagai alternatif dalam proses penilaian perumahan dengan kriteria rumah sehat.

Adapun kriteria - kriteria yang digunakan terlihat pada tabel

TABEL 1

DATA ALTERNATIF

\begin{tabular}{|c|c|c|}
\hline ALT & NAMA & NAMA PERUMAHAN \\
\hline A1 & ASRINI & $\begin{array}{l}\text { PERUM. PURI AGUNG } \\
\text { (SINGGASANA) }\end{array}$ \\
\hline A2 & UMAR ALI & $\begin{array}{l}\text { PERUM. PURI AGUNG } \\
\text { (SINGGASANA) }\end{array}$ \\
\hline A3 & ARIYANTO & $\begin{array}{l}\text { PERUM. PURI AGUNG } \\
\text { (SINGGASANA) }\end{array}$ \\
\hline A4 & SUPINI & $\begin{array}{l}\text { PERUM. PURI AGUNG } \\
\text { (SINGGASANA) }\end{array}$ \\
\hline A5 & ASMAHAN & $\begin{array}{l}\text { PERUM. PURI AGUNG } \\
\text { (SINGGASANA) }\end{array}$ \\
\hline A6 & $\begin{array}{l}\text { DIANTO } \\
\text { SAPUTRA }\end{array}$ & PERUM. METRO \\
\hline A7 & $\begin{array}{l}\text { YUYUN } \\
\text { SURYANI }\end{array}$ & PERUM. METRO \\
\hline A8 & $\begin{array}{l}\text { AHMAD } \\
\text { SEPRIYADI }\end{array}$ & PERUM. METRO \\
\hline A9 & $\begin{array}{l}\text { MUHAMAD } \\
\text { YB, }\end{array}$ & PERUM. METRO \\
\hline A10 & MAIRINI & PERUM. METRO \\
\hline.. &.. & .. \\
\hline A90 & $\begin{array}{l}\text { BARANG } \\
\text { SAPUTRA }\end{array}$ & PERUM. VILLA MUTIARA \\
\hline
\end{tabular}

Adapun kriteria - kriteria yang digunakan terlihat pada tabel 2

TABEL 2

DATA KRITERIA

\begin{tabular}{|l|l|}
\hline KRI & KETERANGAN \\
\hline C1 & KOMPONEN RUMAH (KR) \\
\hline C2 & SARANA SANITASI (SS) \\
\hline C3 & PRILAKU PENGHUNI (PP) \\
\hline
\end{tabular}

Adapun subkriteria - subkriteria yang digunakan terlihat pada tabel 3

TABEL 4

DATA SUBKRITERIA

\begin{tabular}{|l|l|c|}
\hline SUBKRI & KETERANGAN & KRITERIA \\
\hline SC1 & Langit-langit (LL) & \\
\hline SC2 & Dinding (D) & \multirow{2}{*}{ C1 } \\
\hline SC3 & Lantai (L) & \\
\hline SC4 & Jendela kamar tidur (JKT) & \\
\hline
\end{tabular}




\begin{tabular}{|c|c|c|}
\hline SUBKRI & KETERANGAN & KRITERIA \\
\hline SC5 & $\begin{array}{l}\text { Jendela ruang keluarga } \\
\text { (JRK) }\end{array}$ & \\
\hline SC6 & Ventilasi (V) & \\
\hline SC7 & Lubang asap dapur (LAD) & \\
\hline SC8 & Pencahayaan $(\mathrm{P})$ & \\
\hline SC9 & $\begin{array}{l}\text { Sarana pembuangan asap } \\
\text { dapur (SPAD) }\end{array}$ & \multirow{5}{*}{$\mathrm{C} 2$} \\
\hline SC10 & Sarana air bersih $(\mathrm{SAB})$ & \\
\hline SC11 & $\begin{array}{l}\text { Sarana pembuangan kotoran } \\
\text { (SPK) }\end{array}$ & \\
\hline $\mathrm{SC} 12$ & $\begin{array}{l}\text { Sarana pembuangan air } \\
\text { limbah (SPAL) }\end{array}$ & \\
\hline $\mathrm{SC} 13$ & Pengelolaan sampah (PS) & \\
\hline SC14 & $\begin{array}{l}\text { Membuka jendela kamar } \\
\text { tidur (MJKT) }\end{array}$ & \multirow{4}{*}{$\mathrm{C} 3$} \\
\hline SC15 & $\begin{array}{l}\text { Membuka jendela ruang } \\
\text { keluarga (MJRK) }\end{array}$ & \\
\hline SC16 & $\begin{array}{l}\text { Membuang tinja ke jamban } \\
\text { (MTJ) }\end{array}$ & \\
\hline SC17 & $\begin{array}{l}\text { membuang sampah pada } \\
\text { tempat sampah (MSTS) }\end{array}$ & \\
\hline
\end{tabular}

Untuk menentukan derajat kepentingan pada masingmasing alternatif terhadap subkriteria yang ada, fungsi keanggotaan bilangan fuzzy yang digunakan adalah fungsi bilangan fuzzy segitiga, yang mana fungsi keanggotaannya telah dikemukakan pada persamaan (3) yaitu:

$$
\mu A[x]= \begin{cases}0 & ; x<\text { a atau } x>c \\ (x-a) /(b-a) ; & a \leq x \leq b \\ (x-c) /(b-c) ; & b \leq x \leq c\end{cases}
$$

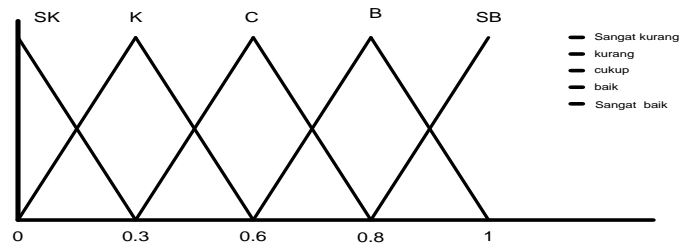

Gambar. 2 Fungsi Keanggotaan Untuk Bobot Setiap Subkriteria Dengan Himpunan Bilangan Fuzzy Segitiga

Variabel linguistik yang memperesentasikan bobot kepentingan untuk setiap subkriteria, adalah : $\mathrm{T}$ ( Kepentingan $\mathrm{W}=\{\mathrm{SK}, \mathrm{K}, \mathrm{C}, \mathrm{B}, \mathrm{SB}\}$ dengan $\mathrm{SK}=$ Sangat Kurang, K=Kurang, $\mathrm{C}=$ Cukup, $\mathrm{B}=\mathrm{Baik}$, $\mathrm{SB}=$ Sangat Baik, yang masing-masing dijabarkan dengan bilangan fuzzy segitiga sebagai berikut:

$$
\begin{array}{ll}
\text { SK } & =(0,0,0.3) \\
\text { K } & =(0,0.3,0.6) \\
\text { C } & =(0.3,0.6,0.8) \\
\text { B } & =(0.6,0.8,1) \\
\text { SB } & =(0.8,1,1)
\end{array}
$$

Untuk menjelaskan grafik fungsi keanggotaan derajat kecocokan alternatif - alternatif dengan subkriteria menggunakan himpunan bilangan fuzzy segitiga.

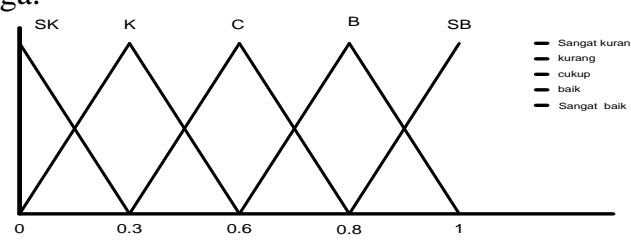

Gambar 3 Fungsi Keanggotaan Untuk Bobot Setiap Subkriteria Dengan Himpunan Bilangan Fuzzy Segitiga

Maka derajat kecocokan alternatif - alternatif dengan kriteria keputusan adalah : $\mathrm{T}$ (kecocokan) $\mathrm{S}=\{\mathrm{SK}, \mathrm{K}$, C, B, SB $\}$ dengan SK = Sangat Kurang, $\mathrm{K}=$ Kurang, $\mathrm{C}=$ Cukup, $\mathrm{B}=$ Baik, $\mathrm{SB}=$ Sangat Baik, yang mana masing-masing dipresentasikan dengan bilangan bilangan fuzzy segitiga sebagai berikut:

Untuk subkriteria SC2, SC9, SC10, SC11 dan SC12 domainnya adalah

$$
\begin{array}{ll}
\text { SK } & =(0,0,0.3) \\
\text { K } & =(0,0.3,0.6) \\
\text { C } & =(0.3,0.6,0.8) \\
\text { B } & =(0.6,0.8,1) \\
\text { SB } & =(0.8,1,1)
\end{array}
$$

Untuk subkriteria SC1, SC3, SC6, SC7, SC8, SC13, SC14, SC15, SC16 dan SC17 domainnya adalah

$$
\begin{array}{ll}
\mathrm{K} & =(0,0.3,0.6) \\
\mathrm{C} & =(0.3,0.6,0.8) \\
\mathrm{B} & =(0.6,0.8,1)
\end{array}
$$

Untuk subkriteria SC4 dan SC5 domainnya adalah

$$
\begin{array}{ll}
\mathrm{K} & =(0,0.3,0.6) \\
\mathrm{B} & =(0.6,0.8,1)
\end{array}
$$

\begin{tabular}{|c|c|c|c|c|c|c|c|c|}
\hline & \multicolumn{8}{|c|}{$\mathrm{C} 1$} \\
\hline Subkriteria & $\mathrm{SC} 1$ & $\mathrm{SC} 2$ & $\mathrm{SC} 3$ & $\mathrm{SC} 4$ & SC5 & SC6 & SC7 & SC8 \\
\hline Rating & B & B & B & B & B & $\mathrm{C}$ & B & B \\
\hline
\end{tabular}

Pemberian bobot untuk setiap alternatif rumah dengan subkriteria dilakukan dengan cara membandingkan skore nilai pada lembar penilaian rumah sehat kemudian memberikan bobot masing-masing subkriteria. Kemudian hasil dari pembobotan subkriteria akan dikalikan dengan bobot kriterianya masing-masing, untuk mendapatkan hasil penilaian akhir sebagai hasil keputusan.

Untuk menentukan bobot kepentingan subkriteria pada setiap kriteria masing-masing yang seperti terlihat pada tabel 4.3 , tabel 4.6 dan tabel 4.7 .

TABEL 5

Rating Kepentingan Untuk Setiap Subkriteria pada Kriteria C1 
TABEL 6

Rating Kepentingan Untuk Setiap Subkriteria pada Kriteria C2.

\begin{tabular}{|l|c|c|c|c|}
\hline Kriteria & \multicolumn{4}{|c|}{ C2 } \\
\hline Subkriteria & SC9 & SC10 & SC11 & SC12 \\
\hline Rating & B & C & C & B \\
\hline
\end{tabular}

TABEL 7

Rating Kepentingan Untuk Setiap Subkriteria pada Kriteria C3

\begin{tabular}{|l|c|c|c|c|c|}
\hline Kriteria & \multicolumn{5}{|c|}{ C3 } \\
\hline Subkriteria & SC13 & SC14 & SC15 & SC16 & SC17 \\
\hline Rating & B & B & B & B & B \\
\hline
\end{tabular}

Untuk keterangan dari tabel diatas yaitu kriteria $\mathrm{C} 1$ (Komponen Rumah), C2 (Sarana Sanitasi), C3(Prilaku Penghuni), dan subkrteria SC1 (Langit-langit), SC2(Dinding), SC3(lantai), SC4(jendela kamar tidur), SC5(jendela ruang keluarga), SC6(ventilasi), SC7(pencahayaan), SC8(sarana pembuangan asap dapur), SC9(sarana air bersih), SC10(sarana pembuangan kotoran, SC11(sarana pembuangan air limbah), SC12(pengeloaan sampah), SC13(membuka jendela kamar tidur), SC14(membuka jendela ruang keluarga), SC15(membersihkan rumah dan halaman), SC16(membuang tinja ke jamban), SC17(membuang sampah pada tempat sampah). Dari beberapa subkriteria yang bobot kepentingan kriterianya yang mempunyai bobot kepentingan Baik(B) yaitu : SC1, SC2, SC3, SC4, SC5, SC7, SC8, SC9, SC12, SC13, SC14, SC15, SC16 dan SC17, dan satu bobot kepentingan Cukup (C) yaitu : SC6, SC10 dan SC11.

TABEL 8

Rating Kepentingan dan Rating Kecocokan Setiap Subkriteria Untuk Alternatif A1 Pada Kriteria C1 (Komponen Rumah).

\begin{tabular}{|c|c|c|c|c|c|c|c|c|c|}
\hline \multirow{5}{*}{$\begin{array}{c}\text { A } \\
1\end{array}$} & & SC & $\mathrm{SC}$ & SC & $\mathrm{SC}$ & SC & SC & SC & SC \\
\hline & Subkriteria & & & 3 & 4 & & 6 & & \\
\hline & $\begin{array}{l}\text { Rating } \\
\text { Kepentinga }\end{array}$ & & & & & & & & $\mathrm{P}$ \\
\hline & & B & B & B & B & B & C & B & B \\
\hline & Kecocokan & B & B & B & B & $\mathrm{C}$ & B & B & B \\
\hline
\end{tabular}

Keterangan untuk tabel 4.8 pada alternatif A1 ( ASRINI ), dengan subkriteria SC1 (langit-langit), SC2 (dinding), SC3 (lantai), SC4 (jendela kamar tidur), SC5 (jendela ruang keluarga), SC6 (ventilasi), SC7 (pencahayaan), SC8 (sarana pembuangan asap dapur). Pada rating kepentingan B (baik), B (baik), B (baik), C (cukup), B (baik), B (baik), B (baik), B (baik). Beserta pada rating kecocokan B ( baik), B (baik), B (baik), B (baik), C (cukup), B (baik), B (baik), B (baik). Dalam melakukan pencarian nilai index kecocokan untuk setiap alternatif $\mathrm{Y} 1, \mathrm{Q} 1, \mathrm{Z} 1$ pada masing-masing rating nilai diambil dari fuzzy segitiga.
Pada Alternatif A1

$$
\begin{aligned}
& Y_{1} \\
& =1 / 8((\mathrm{~B} * \mathrm{~B})+(\mathrm{B} * \mathrm{~B})+(\mathrm{B} * \mathrm{~B})+(\mathrm{B} * \mathrm{~B})+(\mathrm{B} * \mathrm{C}) \\
& +(\mathrm{C} * \mathrm{~B})+(\mathrm{B} * \mathrm{~B})+(\mathrm{B} * \mathrm{~B})) \\
& =1 / 8 *((0.6 * 0.6)+(0.6 * 0.6)+(0.6 * 0.6)+(0.6 * 0.6)+(0.6 * \\
& 0.3))+(0.3 * 0.6)+(0.6 * 0.6)+(0.6 * 0.6))=0.315 \\
& Q_{1} \\
& =1 / 8((\mathrm{~B} * \mathrm{~B})+(\mathrm{B} * \mathrm{~B})+(\mathrm{B} * \mathrm{~B})+(\mathrm{B} * \mathrm{~B})+(\mathrm{B} * \mathrm{C}) \\
& +(\mathrm{C} * \mathrm{~B})+(\mathrm{B} * \mathrm{~B})+(\mathrm{B} * \mathrm{~B})) \\
& =1 / 8 *((0.8 * 0.8)+(0.8 * 0.8)+(0.8 * 0.8)+(0.8 * 0.8)+(0.8 * \\
& 0.6)+(0.6 * 0.8)+(0.8 * 0.8)+(0.8 * 0.8))=0.6 \\
& \mathrm{Z}_{1} \\
& =1 / 8((\mathrm{~B} * \mathrm{~B})+(\mathrm{B} * \mathrm{~B})+(\mathrm{B} * \mathrm{~B})+(\mathrm{B} * \mathrm{~B})+(\mathrm{B} * \mathrm{C}) \\
& +(\mathrm{C} * \mathrm{~B})+(\mathrm{B} * \mathrm{~B})+(\mathrm{B} * \mathrm{~B})) \\
& =1 / 8 *((1 * 1)+(1 * 1)+(1 * 1)+(1 * 1)+(1 * 0.8) \quad)+(0.8 * 1) \\
& +(1 * 1)+(1 * 1))=0.95
\end{aligned}
$$

TABEL 9

Rating Kepentingan dan Rating Kecocokan Setiap Subkriteria Untuk Alternatif A1 Pada Kriteria C2 (Sarana Sanitasi).

\begin{tabular}{|c|l|c|c|c|c|}
\hline \multirow{4}{*}{ A11 } & Subkriteria & SC9 & SC10 & SC11 & SC12 \\
\cline { 2 - 6 } & Rating Kepentingan & B & C & C & B \\
\cline { 2 - 6 } & Rating Kecocokan & SB & B & B & K \\
\hline
\end{tabular}

Keterangan untuk tabel 9 pada alternatif A1 ( ASRINI ), dengan subkriteria SC9 (sarana air bersih), SC10 (sarana pembuangan kotoran), SC11 (sarana pembuangan air limbah), SC12 (pengelolaan sampah). Pada rating kepentingan $\mathrm{B}$ (baik), C (cukup), C (cukup), B (baik). Beserta pada rating kecocokan SB (sangat baik), B (baik), B (baik), K (kurang). Dalam melakukan pencarian nilai index kecocokan untuk setiap alternatif $\mathrm{Y} 1, \mathrm{Q} 1, \mathrm{Z} 1$ pada masing-masing rating nilai diambil dari fuzzy segitiga.

$$
\begin{aligned}
& Y_{1} \\
& =1 / 4((\mathrm{~B} * \mathrm{SB})+(\mathrm{C} * \mathrm{~B})+(\mathrm{C} * \mathrm{~B})+(\mathrm{B} * \mathrm{~K})) \\
& =1 / 4 *((0.6 * 0.8)+(0.3 * 0.6)+(0.3 * 0.6)+(0.6 * 0))=0.21 \\
& Q_{1} \\
& =1 / 4((\mathrm{~B} * \mathrm{SB})+(\mathrm{C} * \mathrm{~B})+(\mathrm{C} * \mathrm{~B})+(\mathrm{B} * \mathrm{~K})) \\
& =1 / 4 *((0.8 * 1)+(0.6 * 0.8)+(0.6 * 0.8)+(0.8 * 0.3))=0.5
\end{aligned}
$$

$\mathrm{Z}_{1}$

$=1 / 4((\mathrm{~B} * \mathrm{SB})+(\mathrm{C} * \mathrm{~B})+(\mathrm{C} * \mathrm{~B})+(\mathrm{B} * \mathrm{~K}))$

$=1 / 4 *((1 * 1)+(0.8 * 1)+(0.8 * 1)+(1 * 0.6))=0.8$

TABEL 10

Rating Kepentingan dan Rating Kecocokan Setiap Subkriteria Untuk Alternatif A1 Pada Kriteria C3 (Prilaku Penghuni).

\begin{tabular}{|c|l|c|c|c|c|c|}
\hline \multirow{4}{*}{ A1 } & Subkriteria & SC13 & SC14 & SC15 & SC16 & SC17 \\
\cline { 2 - 7 } & $\begin{array}{l}\text { Rating } \\
\text { Kepentingan }\end{array}$ & B & B & B & B & B \\
\cline { 2 - 7 } & $\begin{array}{l}\text { Rating } \\
\text { Kecocokan }\end{array}$ & C & B & B & K & B \\
\hline
\end{tabular}

Keterangan untuk tabel 10 pada alternatif A1 (ASRINI), dengan subkriteria SC13 (membuka jendela kamar tidur), SC14 (membuka jendela ruang keluarga), SC15 (membersihkan rumah dan halaman), SC16 (membuang tinja ke jamban), SC17(membuang 
sampah pada tempat sampah). Pada rating kepentingan B (baik), B (baik), B (baik), B (baik), B (baik). Beserta pada rating kecocokan $\mathrm{C}$ (cukup), B (baik), B (baik), K (kurang), B (baik). Dalam melakukan pencarian nilai index kecocokan untuk setiap alternatif Y1, Q1, $\mathrm{Z} 1$ pada masing-masing rating nilai diambil dari fuzzy segitiga.

\section{Pada Alternatif A1}

$Y_{1}$

$=1 / 5((\mathrm{~B} * \mathrm{C})+(\mathrm{B} * \mathrm{~B})+(\mathrm{B} * \mathrm{~B})+(\mathrm{B} * \mathrm{~K})+(\mathrm{B} * \mathrm{~B}))$ $=1 / 5 *((0.6 * 0.3)+(0.6 * 0.6)+(0.6 * 0.6)+(0.6 * 0)+(0.6 * 0$.

6) $))=0.252$

$Q_{1}$

$=1 / 5((\mathrm{~B} * \mathrm{C})+(\mathrm{B} * \mathrm{~B})+(\mathrm{B} * \mathrm{~B})+(\mathrm{B} * \mathrm{~K})+(\mathrm{B} * \mathrm{~B}))$ $=1 / 5 *((0.8 * 0.6)+(0.8 * 0.8)+(0.8 * 0.8)+(0.8 * 0.3)+(0.8 *$ $0.8))=0.528$

$\mathrm{Z}_{1}$

$=1 / 5((\mathrm{~B} * \mathrm{C})+(\mathrm{B} * \mathrm{~B})+(\mathrm{B} * \mathrm{~B})+(\mathrm{B} * \mathrm{~K})+(\mathrm{B} * \mathrm{~B}))$ $=1 / 5 *((1 * 0.6)+(1 * 1)+(1 * 1)+(1 * 0.6)+(1 * 1)))=0.88$

Hasil perhitungan menghasilkan alternatif Y1, Q1, Z1 kriteria C1 (komponen rumah), alternatif Y1, Q1, Z1 kriteria C2 (sarana sanitasi) dan alternatif Y1, Q1, Z1 kriteria C3 (perilaku penghuni).

Untuk perhitungan pencarian setiap alternatif Y1, Q1, Z1 data yang lain sama dengan perhitungan pencarian Y1, Q1, Z1 alternatif A1.

Pada tahap selanjutnya mendistribusikan indeks kecocokn Fuzzy pada tabel 4.11, dan dengan melakukan pengambilan derajat keoptimisan $(\alpha)=0$ (tidak optimis), $(\alpha)=0.5$ dan $(\alpha)=1$ (Sangat Optimis), maka dari itu akan diperoleh suatu nilai integral untuk setiap alternatif. Perhitungan integral subkriteria dihitung pada kriterianya masing-masing.

Perhitungan untuk nilai $(\alpha)$ pada kriteria $\mathrm{C} 1$ (komponen rumah) pada alternatif $\mathrm{A} 1(\mathrm{ASRINI})=0$.

$\mathrm{A}_{1}=\frac{0}{1}=\left(\frac{1}{2}\right) *((0) *(1)+(0.733)+(1-0) *(0.4))$ $=0.5667$

Perhitungan untuk nilai $(\alpha)$ pada kriteria $\mathrm{C} 1$ (komponen rumah) pada alternatif A1 $($ ASRINI $)=0.5$.

$\mathrm{A}_{1}=\mathrm{I} \frac{0}{1}=\left(\frac{1}{2}\right) *((0.5) *(1)+(0.733)+(1-$ $0.5) *(0.4))=0.7167$

Perhitungan untuk nilai $(\alpha)$ pada kriteria $\mathrm{C} 1$ $($ komponen rumah) pada alternatif A1 $($ ASRINI $)=1$.

$\mathrm{A}_{1}=\frac{0}{1}=\left(\frac{1}{2}\right) *((1) *(1)+(0.733)+(1-1) *(0.4))=$ 0.9 .

Perhitungan untuk nilai $(\alpha)$ pada kriteria C2 (sarana sanitasi) pada alternatif A1 $($ ASRINI $)=0$.
$\mathrm{A}_{1}=\frac{0}{\mathrm{I}_{1}}=\left(\frac{1}{2}\right) *((0) *(1)+(0.733)+(1-0) *(0.4))$ $=0.5667$

Perhitungan untuk nilai $(\alpha)$ pada kriteria C2 (sarana sanitasi) pada alternatif A1 (ASRINI) $=0.5$.

$$
\begin{aligned}
& \mathrm{A}_{1}=\mathrm{I} \frac{0}{1}=\left(\frac{1}{2}\right) *((0.5) *(1)+(0.733)+(1- \\
& 0.5) *(0.4))=0.7167
\end{aligned}
$$

Perhitungan untuk nilai $(\alpha)$ pada kriteria C2 (sarana sanitasi) pada alternatif A1 (ASRINI) $=1$

$\mathrm{A}_{1}=\frac{0}{\mathrm{I}_{1}}=\left(\frac{1}{2}\right) *((1) *(1)+(0.733)+(1-1) *(0.4))=$ 0.9

Perhitungan untuk nilai $(\alpha)$ pada kriteria C3 (prilaku penghuni) pada alternatif A1 (ASRINI).

$\mathrm{A}_{1}=\frac{0}{1}=\left(\frac{1}{2}\right) *((0) *(1)+(0.733)+(1-0) *(0.4))$ $=0.5667$

Perhitungan untuk nilai $(\alpha)$ pada kriteria C3 (prilaku penghuni) pada alternatif A1 $($ ASRINI $)=0.5$.

$$
\begin{aligned}
& \mathrm{A}_{1}=\mathrm{I} \frac{0}{1}=\left(\frac{1}{2}\right) *((0.5) *(1)+(0.733)+(1- \\
& 0.5) *(0.4))=0.7167
\end{aligned}
$$

Perhitungan untuk nilai $(\alpha)$ pada kriteria C3 (prilaku penghuni) pada alternatif A1 (ASRINI) $=1$.

$\mathrm{A}_{1}=\frac{0}{1}=\left(\frac{1}{2}\right) *((1) *(1)+(0.733)+(1-1) *(0.4))=$
0.9

Setelah menghitung semua nilai integral pada setiap kriteria, selanjutnya nilai-nilai integral pada masing kriteria dikalikan persentase masing-masing kriteria dan jumlahkan untuk mendapatkan nilai total. persentase kriteria $\mathrm{C} 1$ (komponen rumah) sebesar $31 \%$, kriteria C2 (sarana sanitasi) sebesar $25 \%$ dan kriteria C3 (prilaku penghuni) sebesar $44 \%$.

Setelah dilakukan analisis perulangan data dan pengujian terhadap semua hasil perhitungan manual yang ada dengan menggunakan Fuzzy nilai total integral, dan didapatkan hasil perhitugan manual yang dapat dipertegas kebenarannya oleh penulis.

Jadi dari hasil perhitungan yang telah dilakukan, maka alternatif penilaian perumahan dengan kriteria rumah sehat akan digabung nilai total penilaian menurut letak perumahannya masing-masing dan dibandingkan dengan nilai kategori layak yaitu 8.714 untuk mendapatkan status layak dan tidak layak pada tabel 11 . 
TABEL 10

Nilai Perangkingan Perumahan

\begin{tabular}{|l|l|l|l|}
\hline NO & Perumahan & Total Nilai & Keterangan] \\
\hline 1 & PERUM. PURI ANGSA & 9.087 & Layak \\
\hline 2 & $\begin{array}{l}\text { PERUM. KASANG } \\
\text { PUDAK PERMAI }\end{array}$ & 8.920 & Layak \\
\hline 3 & $\begin{array}{l}\text { PERUM. MAWAR PUTIH } \\
2\end{array}$ & 8.920 & Layak [7] \\
\hline 4 & $\begin{array}{l}\text { PERUM. TANJUNG } \\
\text { NANGKO PERMAI }\end{array}$ & 8.920 & Layak \\
\hline 5 & PERUM. FATIMAH 1 & 8.920 & Layak \\
\hline
\end{tabular}

Jadi dari hasil perhitungan yang telah dilakukan, maka perumahan yang mempunyai nilai tertinggi adalah Perum. Puri Anggsa yang mana perumahan ini merupakan alternatif dari perumahan yang ada dengan mendapatkan perhitungan nilai tertinggi menurut perhitungan perumahan dengan kriteria rumah sehat.

\section{KESIMPULAN}

1. Dengan menggunakan Sistem Pendukung Keputusan serta metode Fuzzy Multi Criteria Decision Making ini dapat digunakan pada kasus yang banyak menggunakan kriteria untuk menyelesaikan permasalahan yang ada.

2. Penerapan metode Fuzzy Multi Criteria Decision Making sangat membantu dalam penilaian perumahan dengan kriteria rumah sehat di Desa Kasang Pudak untuk membantu pemerintah dalam menilai perumahan yang layak huni bagi masyarakat.

3. implementasi dalam menyamakan hasil perhitungan manual serta dari sistem harus dilakukan agar mengetahui ada atau tidak nya perbedaan hasil, serta penggunaan aplikasi sistem pendukung keputusan yang dibuat dengan bahasa pemrograman PHP dan database MySQL.

\section{REFERENSI}

[1] Anjali, et al (2011). A multi-criteria decision making approach for location planning for urban distribution centers under uncertainty, Mathematical and computer modelling.

[2] Retantyo Wardoyo dan Rika Rosnelly (2011). Penerapan Fuzzy Multi Criteria Decision Making (FMCDM), Seminar Nasional Informatika(2011). ISSN 1979-2328.

[3] Cang, Tsun-Han, et al (2009). Using the fuzzy multi-criteria decision maiking approach for measuring the possibility of successful knowledge management, Information Science 179 (2009) 355-370

[4] Jurgita Antucheviciene, et al (2015). Decision Making Methods and Applications in Civil Enginering.Hindawi Publishing Corporation Mathematical Problem in Engineering Volume 2015. Article ID 160569.

[5] Richard Edger Hodgett (2015). Comparison of Multi-Criteria Decision Making Methods for
Equipment Selection, International Journal of Advanced Manufacturing Technology.

Cengiz Kahraman, et al (2015). Fuzzy Multi Criteria Decision Making : A Literature Review, International Journal of Advanced Manufacturing Technology.

Rahmat Hidayat (2015) Sistem Pendukung Keputusan Unr=tuk Menetukan Ketua Petugas Guru Piket Dengan Menggunakan Metode Analytical Hierarcy Process (AHP) (Study Kasus SDN 106166 Marindal), Pelita Informatika Budi Darma, Volume: IX, Nomor: 1, (Maret 2015). ISSN 2301-9425.

[8] Zulkifli (2013). Sistem Pendukung Keputusan Penentuan Peserta Jamkesmas Dengan Metode Simple Additive Weighting (Studi Kasus : Desa Dalu Sepuluh A), Pelita Informatika Budi Darma, Volume:V, Nomor :1, November 2013. ISSN 2301-9425.

[9] Wulandari Novita Endah (2015).Sistem Pendukung Keputusan Penentun Karywan (Agen) Terbaik Menggunakan Metode Analytical Hierarchy Process (AHP) (Studi Kasus : Kantor Cabang AJB Bumiputera 1912 LubukPakam).Pelita Informatika Budi Darma, Volume:IX, Nomor :3, April 2015. ISSN : 23019425.

[10] Sidiq Akhmad Fadjar dan Munarwan (2012). Sistem pendukung Keputusan Menggunakan Metode Technique for Order by Similiarity to Ideal Solution (TOPSIS) Jurnal Sistem Informasi (JSI), Vol.4 No.1, April 2012 ISSN Print: 2085 1588, ISSN Online : 2355 -4614

[11] Amelia Yusnita dan Rosiana Handini (2012).Sistem Pendukung Keputusan Menetukan Lokasi Rumah Makan Ynag Strategis Menggunakan Metode Nä̈ve Bayes. Seminar Nasional Teknologi Informasi \& Komunikasi Terapan 2012(Semantik 2012) ISBN.979-260255-0.

[12] Dita Monita (2013). Sistem Pendukung Keputusan Penerima Bantuan Langsug Tunai Dengan Menggunakan Metode Analytical Hierarcy Process.. Pelita Informatika Budi Darma, Volume III Nomor :2. ISSN : 2301-9425.

[13] Sudiyantoro Dalam Amelia Yusnita dan Rosiana Handini (2012).Sistem Pendukung Keputusan Menetukan Lokasi Rumah Makan Ynag Strategis Menggunakan Metode Nä̈ve Bayes. Seminar Nasional Teknologi Informasi \& Komunikasi Terapan 2012(Semantik 2012) ISBN.979-260255-0..

[14] Fulop Dalam Sri Andayani Dan Djemari Mardapi (2012), Performance Assessment Dalam Perspektif Multiple Criteria Decision Making, Prosiding Seminar Nasional Penelitian, Pendidikan Dan Penerapan MIPA, Fakultas MIPA, Universitas Negeri Yogyakarta.

[15] Rinto Lissa et al (2015).Kombinasi Algoritma Peramalan Indeks Musim Dan Pengembangan Fuzzy- MCDM Dalam Memprediksi Kecocokan 
Tanaman Pangan Di Salatiga (2015). Seminar Nasional Sistem Informasi Indonesia .

[16] Rika Rosnelly Dan Retantyo Wardoyo (2011) Penerapan Fuzzy Multi Criteria Decision Making (FMDCM) Untuk Diagnosis Penyakit Tropis. Seminar Nasional Informatika 2011. ISSN : 1979 -2328 . 